\title{
Erratum to: Integrating Social-Scientific Literacy in Nuclear Engineering Education
}

\section{Approaches Developed in the GoNERI Program}

\author{
Kohta Juraku, Cathryn Carson, Shinya Nagasaki, \\ Mikael Jensen, Joonhong Ahn and Satoru Tanaka
}

\section{Erratum to:}

Chapter 1 in: J. Ahn et al. (eds.), Reflections on the

Fukushima Daiichi Nuclear Accident, DOI 10.1007/978-3-319-12090-4_1

Part of this chapter was supported by Prof. Tatsuhiro Kamisato and it was unfortunately not acknowledged in the original version.

The online version of the original chapter can be found under DOI 10.1007/978-3-319-12090-4_1

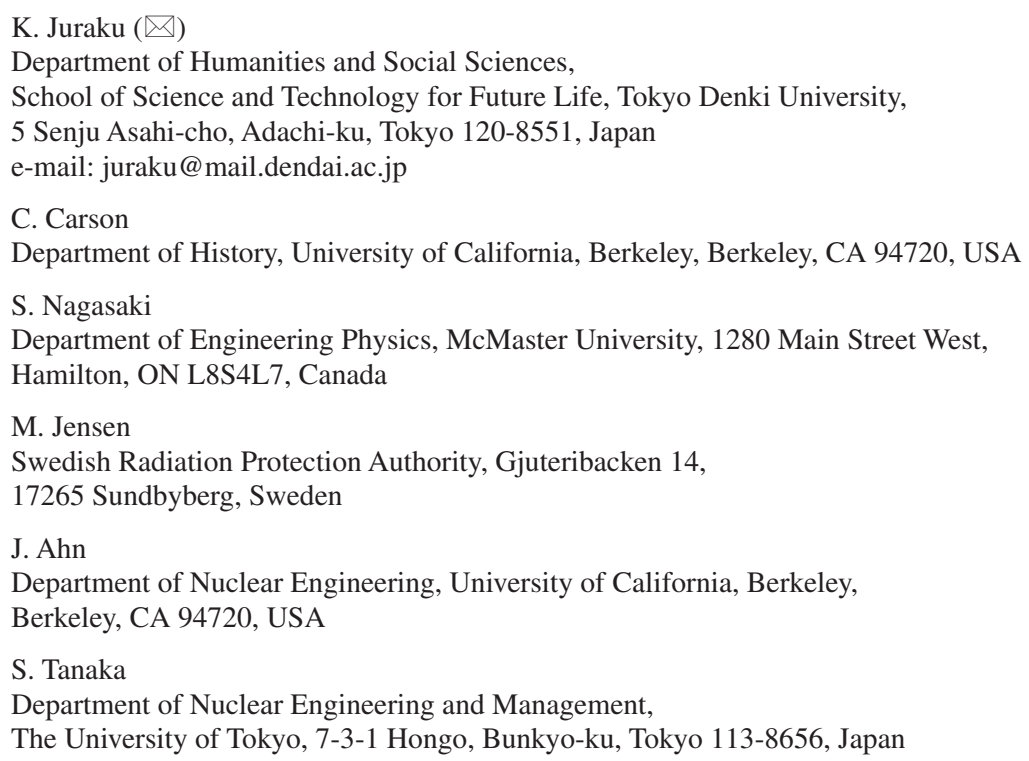


The following texts to be inserted at the end of the acknowledgement of Chap. 1.

Part of Section 1.4 was drafted by Prof. Tatsuhiro Kamisato in Japanese. The authors of this chapter are very much grateful for his permission to use his contribution in this chapter.

Open Access This chapter is distributed under the terms of the Creative Commons Attribution Noncommercial License, which permits any noncommercial use, distribution, and reproduction in any medium, provided the original author(s) and source are credited. 